\title{
Correction
}

\section{Correction to: Characterization of oogonia stem cells in mice by Fragilis}

\author{
Xiaoyan Sheng ${ }^{1,2}$, Chenglei Tian ${ }^{1,2}$, Linlin Liu ${ }^{1,2}$, Lingling Wang ${ }^{1}$, \\ Xiaoying $\mathrm{Ye}^{1,2}$, Jie $\mathrm{Li}^{1,2}$, Ming Zeng ${ }^{1}$, Lin Liu ${ }^{1,2}$ \\ ${ }^{1}$ State Key Laboratory of Medicinal Chemical Biology, College of Life Sciences, Nankai University, Tianjin 300071, China \\ 2 Department of Cell Biology and Genetics, College of Life Sciences, Nankai University, Tianjin 300071, China \\ $\bowtie$ Correspondence: liulin@nankai.edu.cn (L. Liu)
}

Correction to: Protein Cell 2019, 10(11):825-831

https://doi.org/10.1007/s13238-019-00654-0

In the original publication the labelling on Fig. $2 A$ and $B$ were incorrectly published as E7.5. The correct labelling of Fig. 2A and $B$ should be read as E17.5 which is provided in this correction. 
A

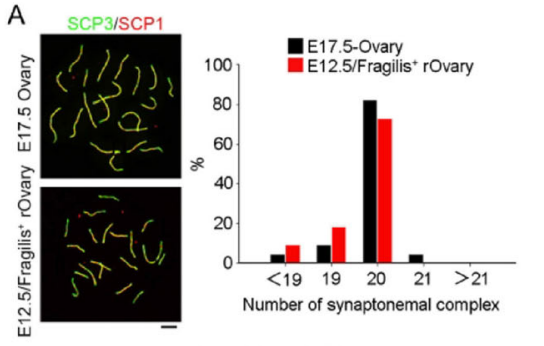

$\mathrm{C}$

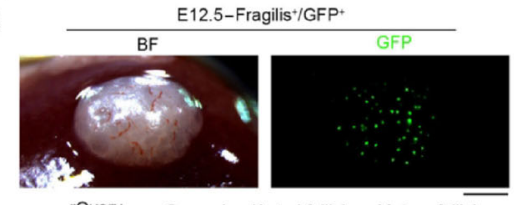

rOvary Secondary/Antral follicles Mature follicles
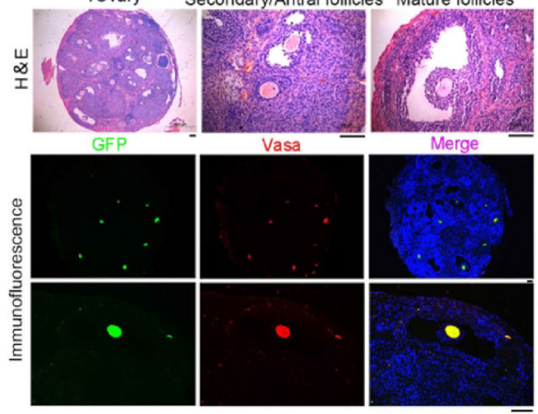

E

GV oocytes

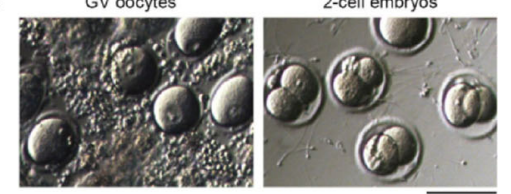

G

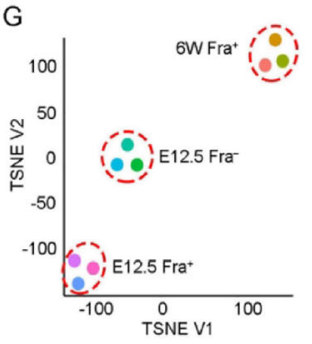

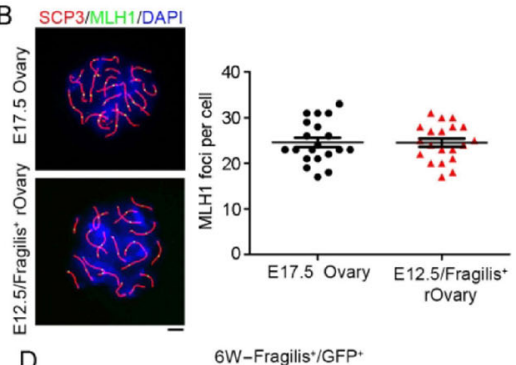
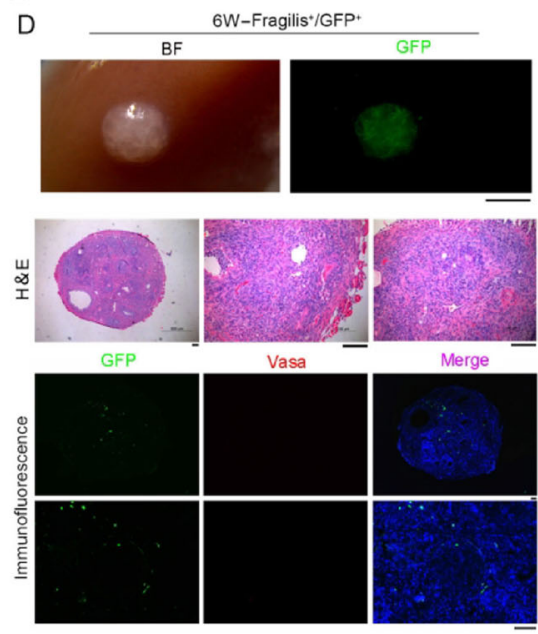

$\mathrm{F}$

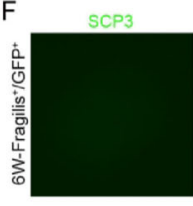

$S C P 1$

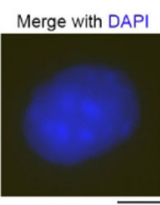

I PGC and germ cell marker Proliferation marker marker
Gonad somatic cell marker

- Down-regulation $\bullet$ No change $\bullet$ Up-regulation E12.5 Fra+ vs E12.5 Fra-

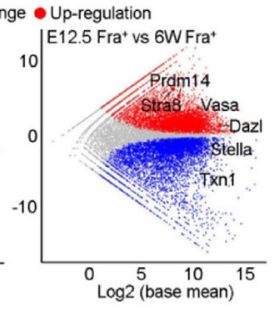


Figure 2. Neo-meiosis and functional test of oocytes developed from Fragilis ${ }^{+}$cells. (A) Immunofluorescence of SCP1 (red) and SCP3 (green, appear as yellowish by merge with SCP1) showing pachytene spread of E12.5 Fragilis $^{+}$cells obtained from aggregates with fetal E12.5 somatic cells 6 days following transplantation, compared with those of E17.5 ovaries. Right panel, Percentage of synaptonemal complex elements based on count of spread at pachytene $(n=22)$. Scale bar $=5 \mu \mathrm{m}$. (B) Representative immunofluorescence of MLH1 foci at pachytene stage by co-immunostaining of SCP3 (red) and MLH1 (green). Right panel, Statistics of MLH1 foci represents 20 spread per each group. Scale bar $=5 \mu \mathrm{m}$. (C) Morphology of reconstituted ovaries 28 days following transplantation of E12.5 Fragilis $^{+}$cells aggregated with E12.5 gonadal somatic cells into kidney capsules of ovariectomized mice $(n=8)$. Scale bar $=1 \mathrm{~mm}$ (upper panel). Middle panel, Follicles are shown in sections by H\&E staining. Scale bar $=100 \mu \mathrm{m}$. Bottom panel, Co-immunostaining of GFP (green) and Vasa (red) in reconstituted ovaries. BF, bright-field. Nuclei were stained in blue by Hoechst. Scale bar $=100 \mu \mathrm{m}$. (D) Morphology of grafts 28 days following kidney capsule transplantation of 6-week Fragilis $^{+}$cells aggregated with E12.5 gonadal somatic cells $(n=3)$. No follicles but $\mathrm{GFP}^{+}$somatic cells are seen. (E) Morphology of GV oocytes isolated from reconstituted ovaries developed from E12.5 Fragilis $^{+}$cells aggregated with E12.5 gonadal somatic cells, and 2-cell embryos following in vitro maturation (IVM) and fertilization (IVF). (F) Immunofluorescence of SCP1 (red) and SCP3 (green) in aggregates obtained from 6 -week old Fragilis ${ }^{+}$cells with fetal E12.5 gonadal somatic cells 6 days following transplantation. Scale bar $=10 \mu \mathrm{m}$. $(\mathrm{G}-\mathrm{I})$ Transcriptome of Fragilis $^{+}$and Fragilis ${ }^{-}$cells sorted from E12.5 ovaries and Fragilis $^{+}$cells from 6 -week old mouse ovaries. (G) TSNE of global gene expression profiles of Fragilis $^{+}$cells sorted from fetal ovaries $\left(\mathrm{E} 12.5 \mathrm{Fra}^{+}\right)$, Fragilis ${ }^{-}$cells sorted from fetal ovaries (E12.5 $\left.\mathrm{Fra}^{-}\right)$and Fragilis ${ }^{+}$cells sorted from 6-week ovaries $\left(6 \mathrm{~W} \mathrm{Fra}^{+}\right)$. (H) Scatter plots comparing transcriptome among these three cell populations. Parallel diagonal lines indicate threshold in expression difference. Red, up-regulated genes in E12.5 $\mathrm{Fra}^{+}$cells; blue, down-regulated genes in E12.5 $\mathrm{Fra}^{-}$or in $6 \mathrm{~W} \mathrm{Fra}{ }^{+}$cells. (I) Heatmap highlighting gene expression profile of germ cells, proliferation and gonad somatic cells.

\section{OPEN ACCESS}

This article is licensed under a Creative Commons Attribution 4.0 International License, which permits use, sharing, adaptation, distribution and reproduction in any medium or format, as long as you give appropriate credit to the original author(s) and the source, provide a link to the Creative Commons licence, and indicate if changes were made. The images or other third party material in this article are included in the article's Creative Commons licence, unless indicated otherwise in a credit line to the material. If material is not included in the article's Creative Commons licence and your intended use is not permitted by statutory regulation or exceeds the permitted use, you will need to obtain permission directly from the copyright holder. To view a copy of this licence, visit http:// creativecommons.org/licenses/by/4.0/. 